\title{
Resistance to cancer treatment: the role of somatic genetic events and the challenges for targeted therapies
}

\section{Gerald Batist ${ }^{1,2,3}{ }^{*}$, Jian Hui Wu ${ }^{1,2,3}$, Alan Spatz ${ }^{1,2,3,4}$, Wilson H. Miller Jr. ${ }^{1,2,3}$, Eftihia Cocolakis ${ }^{1}$, Caroline Rousseau ${ }^{3}$, Zuanel Diaz ${ }^{3}$, Cristiano Ferrario ${ }^{1,2,3}$ and Mark Basik ${ }^{1,2,3,5}$}

\author{
1 Segal Cancer Center, Jewish General Hospital, Montreal, OC, Canada \\ ${ }^{2}$ Department of Oncology, McGill University, Montreal, OC, Canada \\ ${ }^{3}$ Quebec Consortium de Recherche en Oncologie Clinique, Montreal, OC, Canada \\ ${ }^{4}$ Department of Pathology, Mc Gill University, Montreal, OC, Canada \\ ${ }^{5}$ Department of Surgery, Mc Gill University, Montreal, OC, Canada
}

Edited by:

Alexandre Arcaro, University of Bern,

Switzerland

\section{Reviewed by:}

Olivier Micheau, INSERM, France

Jonathan Harris, Queensland

University of Technology, Australia

*Correspondence:

Gerald Batist, Department of

Oncology, Segal Cancer Centre,

McGill University, 3755 Cote Sainte

Catherine Road, Montreal, QC,

Canada H3T 1 E2.

e-mail: gerald.batist@mcgill.ca
Therapeutic resistance remains a major cause of cancer-related deaths. Resistance can occur from the outset of treatment or as an acquired phenomenon after an initial clinical response. Therapeutic resistance is an almost universal phenomenon in the treatment of metastatic cancers. The advent of molecularly targeted treatments brought greater efficacy in patients whose tumors express a particular target or molecular signature. However, resistance remains a predictable challenge. This article provides an overview of somatic genomic events that confer resistance to cancer therapies. Some examples, including BCR-Abl, EML4-ALK, and the androgen receptor, contain mutations in the target itself, which hamper binding and inhibitory functions of therapeutic agents. There are also examples of somatic genetic changes in other genes or pathways that result in resistance by circumventing the inhibitor, as in resistance to trastuzumab and BRAF inhibitors. Yet other examples results in activation of cytoprotective genes. The fact that all of these mechanisms of resistance are due to somatic changes in the tumor's genome makes targeting them selectively a feasible goal. To identify and validate these changes, it is important to obtain biopsies of clinically resistant tumors. A rational consequence of this evolving knowledge is the growing appreciation that combinations of inhibitors will be needed to anticipate and overcome therapeutic resistance.

Keywords: cancer, somatic genetic events, BCR-Abl, EML4-ALK
The fundamental challenge in all anti-cancer therapeutics is resistance. This is true of all forms of therapy, in early disease and in advanced metastatic cancers. It may be reflected as either intrinsic or acquired therapeutic resistance. While the problem with regards to classical cytotoxic treatments has been studied for decades in various experimental models, few of the mechanisms or models of resistance have been clearly shown to play a decisive role in the clinical setting, and still fewer are amenable to manipulation in order to overcome resistance.

The goal is to identify what are often multiple mechanisms of resistance in a detection system with "clinical utility." Notwithstanding gene expression assays and protein-based studies, DNAbased tests remain the most robust. Indeed inter-observer and inter-platform variability appear to be much greater problems with the former two technologies (Press et al., 2005; Mackay et al., 2011). Identifying mutations and generating multiplexed assays is a very realistic goal for clinically useful tools. However, to date few somatic genetic events have been confirmed in clinical samples as drivers of therapeutic resistance, mostly due to the dearth of tissue samples from resistant tumors. This article provides a brief outline of the role of genomic mutations in therapeutic resistance to "targeted" anti-cancer therapies.

The advent of targeted agents generates much enthusiasm because of enhanced efficacy and reduced toxicity, yet therapeutic resistance remains a core challenge. For instance, amongst the most startling targeted agents of the recent decade is the small molecule kinase inhibitor Imatinib (Gleevec), which targets the BCR-Abl fusion gene that drives chronic myelogenous leukemia. This drug binds and inhibits the oncogene's growth promoting function, and was so effective that it moved to regulatory approval and the clinic in unprecedented time. The target was clear, and thus the inevitable resistance was predictably the result of somatic mutations in the target, the kinase domain of BCR-Abl (Shah et al., 2002). A fairly restricted number of mutations are responsible for conformational changes in the target, and so medicinal chemists devised new chemical structures that became the next generations of effective inhibitors (Hochhaus et al., 2007).

A second example of a druggable gene fusion somatic event, and the first in solid tumors, is the EML4-ALK gene fusion found in $5 \%$ of non-small cell lung cancers (NSCLC). Crizotinib is a small molecule ALK inhibitor which has showed excellent clinical results in patients whose lung tumors carry the ALK gene fusion. Similarly to the imatinib story, two recent reports have discovered secondary mutations in the kinase domain of the ALK gene that appear to be responsible for resistance to crizotinib and also to two other unrelated ALK inhibitors (Choi et al., 2010; Sasaki et al., 2011). Interestingly, both the site of one of the secondary mutations in the ALK kinase domain reported by Choi et al. (2010), and 
of secondary mutations found in the Abl kinase, are located at the bottom of the ATP binding pockets of these respective kinases.

Mutations in the target are responsible for therapeutic resistance in much older targeted agents as well, such as one of the oldest such class of agents, the antiandrogens used to treat prostate cancer. The proliferation and survival of prostate cancer cells is critically dependent on androgen receptor (AR) signaling axis (Balk, 2002; Culig et al., 2002). Androgen ablation therapy is the current mainstay treatment for advanced prostate cancer. This method aims to suppress AR activation by reducing testicular androgen secretion via castration and/or by disrupting the binding of androgens to AR using antiandrogens, such as flutamide, nilutamide, and bicalutamide. Despite initial response, most patients progress to a lethal disease state called castration resistant prostate cancer (CRPC; Taplin and Ho, 2001). To date, the median survival time for patients with established CRPC is $<2$ years (Petrylak et al., 2004; Tannock et al., 2004). Emerging biological observations in prostate cancer have indicated that most CRPC cells are still dependent on the AR signaling for proliferation and survival, and in CRPC cells, the AR is activated by multiple mechanisms that cannot be effectively suppressed by castration and currently clinically used antiandrogens (Agoulnik and Weigel, 2006). In particular, mutations in AR render the AR promiscuous so that it can be activated by a broad range of nonandrogen ligands, even antiandrogens (Krishnan et al., 2002). The incidence of AR mutation in prostate cancer is estimated to be in the range of 10-40\% (Taplin et al., 2003; Miyamoto et al., 2004; Taplin, 2008). A series of AR mutations, such as T877A, H874Y, W741C, $\mathrm{L} 701 \mathrm{H}$, and V715M were identified from tissue specimens of CRPC patients, and found to produce mutated ARs which can be activated by a series of non-androgen ligands (Chang et al., 2001; Krishnan et al., 2002). In cellular models, the T877A and H874Y mutated ARs are paradoxically activated by hydroxyflutamide, an active metabolite of the anti-androgen drug flutamide (Steketee et al., 2002). The T877A mutant is activated by nilutamide (Urushibara et al., 2007), and the W741C mutant is paradoxically activated by bicalutamide (Hara et al., 2003). Significantly, the T877A and W741C mutations were found in patients who experienced treatment failure with flutamide and bicalutamide, respectively (Taplin et al., 2003). It appears that novel antiandrogens effective against the wild type AR and multiple mutated ARs represent an attractive strategy for combating resistance to currently clinically used antiandrogens (Zhou et al., 2009). Other novel anti-androgen therapies such as abiraterone, which target androgen production in peripheral tissue, demonstrate significant clinical benefits. This contributes to the case that there are likely multiple mechanisms of resistance, but most importantly, that the AR is still operational even CRPC patients (Ryan and Tindall, 2011).

It is likely a function of the importance of both BCR-Abl in $\mathrm{CML}$ and $\mathrm{AR}$ in prostate cancer that mutations in these targets themselves are the most common mechanisms of therapeutic resistance to these targeted therapeutic agents. There are, in contrast, many other contexts in which the target of a clinically effective therapy is known, and mutations of the target itself do not appear to play a role in the development of resistance, although other somatic genetic events appear to do so.
The antibody trastuzumab was developed to target HER2 overexpressing breast cancer resulting from amplification of the gene (15\%), and is effective in the adjuvant setting, and less so to treat metastatic disease. It is always combined with cytotoxic chemotherapy, which results in significant efficacy (Jackisch, 2006; Bartsch et al., 2007). Therefore, early stage breast cancer patients routinely have quantitative analysis of HER2 to guide the addition of trastuzumab. The adjuvant use of trastuzumab plus chemotherapy in breast cancer does not benefit up to $15 \%$ of cases, suggesting the presence of intrinsic resistance (Gianni et al., 2011). The biological implication is that HER2 amplification is not a dominant or driver modification in these patients' tumors.

Although many mechanisms of resistance to trastuzumab have been discovered in pre-clinical models, including the activation of downstream signaling pathways [AKT (Nahta and O'Regan, 2010), SRC (Zhang et al., 2011), PKA (Gu et al., 2009)], as well as somatic genetic events such as the co-amplification of oncogenes (e.g., MYC), deletions in tumor suppressor genes (e.g., PTEN; Christodoulou et al., 2009), mutations in components of HER signaling (e.g., PIK3CA (Kataoka et al., 2010)), none of these have yet passed the test of clinical validation. Indeed, there is significant doubt about the clinical existence of acquired resistance to trastuzumab, underlying the current practice of continuing trastuzumab while changing that cytotoxic chemotherapy given in combination with it (Chang et al., 2001; Taplin et al., 2003; Miyamoto et al., 2004; Taplin, 2008; Christodoulou et al., 2009; Gu et al., 2009; Nahta and O'Regan, 2010; Zhang et al., 2011) upon tumor progression. It may be more difficult to overcome the effect of multiple copies of the ERBB2 gene, as well as, perhaps, of genes accompanying it on the 17q12-21 amplicon, than that of an activating mutation in a single oncogene. More recently, evidence has emerged demonstrating a clinical benefit of adding trastuzumab to chemotherapy in the $10-15 \%$ of gastric carcinomas that have amplification of HER2 using FISH analysis (Fornaro et al., 2011). While clinical responses are more frequent and durable in these patients, they all do relapse, and the mechanism of resistance is unknown.

Large scale sequencing of cancer genomes led to the discovery of activating mutations in the serine threonine kinase BRAF in patients with melanoma (Davies et al., 2002). A substitution of glutamic acid for valine amino acid 600 (V600E) encompasses $90 \%$ of BRAF mutations and causes a 500 -fold increase in activity in comparison to the wild type protein (Wan et al., 2004). This led to the development of novel mutant BRAF targeted therapies, including RG7204/OR5185426 (Plexxikon/Roche), GSK2118236 (Glaxo Smith Kline), RAF265 (Novartis), and XL-281 (Bristol Myers Squibb). These compounds are in clinical trials, and some have already produced startling clinical response rates in comparison to standard chemotherapy (Kefford et al., 2010; Chapman et al., 2011; Sharfman et al., 2011). However, these responses are short lived and patients relapse within 8-12 months.

The mechanisms of BRAF inhibitor resistance can be intrinsic or acquired, since not all patients respond, but many responders do relapse. To date secondary mutations in BRAF have not been found in either pre-clinical or clinical samples of resistant melanomas. In melanoma cells, constitutive BRAF/MEK/ERK signaling drives cell cycle entry and uncontrolled growth by increasing cyclin 
D1 expression. Pre-clinical data suggests that increased cyclin D1 expression can mediate BRAF inhibitor resistance in BRAF V600E mutated melanomas (Smalley et al., 2008). This is of particular interest given the recent demonstration of the cyclin D1 is involvement in DNA repair (Jirawatnotai et al., 2011) and that cyclin D1 amplification has been reported in as many as 32\% of primary melanomas, although its incidence may be less in metastatic tumors (Lázár et al., 2009). Melanomas can also acquire resistance through a variety of putative mechanisms, including activation of alternative survival pathways via receptor and nonreceptor tyrosine kinases (such as PDGFR $\beta$, IGF-1R, and COT), RAS-mediated reactivation of the MAPK pathway and a switch in signaling through other RAF isoforms (Johannessen et al., 2010; Nazarian et al., 2010). A recent report also found that mutations in NRAS may lead to acquired resistance to anti-BRAF targeted agents (Nazarian et al., 2010). In one of 16 patients, an NRAS mutation appeared after progression during treatment with PLX4032, a BRAF inhibitor. The patient was continued on therapy, and another lesion that subsequently appeared showed a distinct NRAS mutation. Interestingly, both mutations were associated with an increase in NRAS DNA copy number. The NRAS gene is mutated in about $20 \%$ of primary melanomas (Lázár et al., 2009), and apparently never simultaneously with a BRAF mutation.

In a recent report by Villanueva et al. (2010) the acquisition of BRAF inhibitor resistance led to a recovery of MAPK signaling and was associated with an increase in CRAF protein expression (Montagut et al., 2008; Fedorenko et al., 2011). This flexible switching between RAF isoforms led to cross-resistance with other BRAF inhibitors and was not associated with acquired secondary mutations in BRAF, NRAS, or PTEN. In fact the RAF isoform switching it not an example of a somatic genetic change associated with resistance, but more likely a post-transcriptional change. This is a good example of how studying therapeutic resistance to targeted agents can provide opportunities to learn about biological functions.

These resistance pathways are potentially targetable. For example, combining inhibitors of PI3K or IGF-1R with a MEK inhibitor could overcome resistance in several BRAF refractory cells (Villanueva et al., 2010). Several studies have now identified BRAF amplification as a mechanism for MEK inhibitor resistance in BRAF or K-RAS mutant cells and a recent study identified an activating mutation at codon 121 in the downstream kinase MEK1 which increased kinase activity and conferred robust resistance to combined MEK/RAF inhibition. Interestingly, this mutation that was absent in the corresponding pre-treatment tumor (Little et al., 2011; Wagle et al., 2011). For patients with BRAF mutant tumors, the results also provide a mechanistic basis for trials testing concurrent treatment with both RAF and MEK inhibitors. Such trials are currently accruing patients with BRAF mutant metastatic melanoma (clinicaltrials.gov identifiers NCT01072175 and NCT01231594), and the results are eagerly awaited. In summary, new strategies are needed to treat patients with melanomas carrying the BRAF V600E mutation in whom resistance to antiBRAF develops (Corcoran et al., 2010). These are mainly based on the combined inhibition of MEK and RAF. But resistance that is caused by mutations affecting RAS proteins may be more difficult to treat because attempts to develop direct inhibitors of RAS have all met with failure. The combined inhibition of MEK and RAF will not affect the activation of other RAS targets. Inhibitors of MEK have also been found to have clinical activity in melanoma and are now being tested in patients with BRAF inhibitor resistance (Dummer et al., 2008; Infante et al., 2011).

The example of reversion of BRCA2 mutations is an unusual and striking instance of a somatic genetic event underlying the development of therapeutic resistance (Sakai et al., 2008). Sakai et al. (2008) found that breast cancer and pancreatic cancer cell lines carrying BRCA2 mutations and that had developed therapeutic resistance to either cisplatin or the PARP inhibitor AG14361 were found to have re-activated BRCA2 through the development of secondary intragenic mutations. Moreover, in two of five patients with ovarian carcinoma whose tumors had become resistant to cisplatin, genetic reversion to a normal BRCA2 allele was found in one resistant tumor and selection for loss of the mutant BRCA2 allele was found in another one. The authors speculated that cisplatin treatment itself could enable secondary mutations because of its DNA damaging effect. Another hypothesis is that as BRCA2 is involved in DNA repair and homologous recombination, BRCA2 deficiency itself in these tumors may promote the formation of secondary mutations.

EGF receptor (HER-1) represents another important target that has been addressed therapeutically, since it is overexpressed in a number of cancers and is associated with aggressive behavior, advanced disease and resistance to standard therapies (Baselga and Mendelsohn, 1997). Two different approaches have been taken, and each has proven therapeutic efficacy in distinct contexts: (i) antibodies that effectively compete with the ligand binding (Erbitux, Panitumumab), for the treatment of metastatic colorectal cancer and regional head and neck cancer, (ii) small molecules that compete for ATP binding in the kinase domain of the receptor (erlotinib, gefitinib), with activity in a subset of patients with NSCLC.

Mutations play interesting and distinct roles in these two contexts. In the case of the small molecules, genomic sequencing of responding tumors demonstrated distinct mutations in the kinase domain of the EGF receptor, most often in exons 19 and 21 (Lynch et al., 2004; Paez et al., 2004). These mutations enhance ATP binding, resulting in "addiction" of the tumor to EGFR-driven phosphorylation, and enhanced sensitivity to the inhibitors. Hence in this context mutations in the target signal enhanced sensitivity. Yet, a distinct mutation has been demonstrated in clinically relapsing tumors, which had initially responded to the small molecules (Wu et al., 2008), and so the specificity of the mutations is critical in this scenario.

The anti-EGFR antibodies present yet another scenario of therapeutic resistance. The key initial finding was that an activating mutation in a downstream protein in the EGFR signaling pathway, in particular K-RAS, is associated with clinical resistance to these antibodies targeting the ligand binding domain. In an interesting exception, mutations in particular domains of K-RAS do not predict resistance, as most recent data has shown (KhambataFord et al., 2007; De Roock et al., 2010). Also, activating mutations further downstream, in BRAF, or in an alternative and parallel pathway, PI3Kinase, may also select tumors that are unresponsive to anti-EGFR antibodies (Sartore-Bianchi et al., 2009; Berg 
et al., 2010), although the evidence is so far not clinically validated since these antibodies are generally given together with chemotherapy, making it difficult to identify resistance specifically to the antibody.

While still generally considered non-specific compared to newer "targeted agents," a strong case can be made that many cytotoxic drugs exert their anti-tumor effect through specific or a finite number of molecular targets, just as targeted agents often modulate more than one molecule. The role of DNA repair genes in effecting resistance to DNA damaging agents such as cisplatin has been highlighted above. Some targets of cytotoxic drugs include tubulin components in the case of taxanes or vinca alkaloids, a specific topoisomerase isoform for doxorubicin, etc. Experimental models have pointed to a variety of explanations for resistance that have focused on cell survival and detoxification as opposed to alterations in the targets. Clinical studies have not confirmed that modifying any single one of these can overcome resistance. More recently attention has turned to master transcription factor called Nuclear factor erythroid-2 related factor-2 (Nrf2), which regulates a cytoprotective gene program that includes a large number of these mechanisms. The level of Nrf2 protein available to translocate to the nuclear and activate the program is regulated through its physical interaction with Klech-like ECH-associated protein 1 (Keap1), which functions as an adapter protein that targets Nrf2 to Cullin 3 ubiquitin E3 ligase (Cul3), and the proteosome for degradation (Loignon et al., 2009). Some sub-types of the generally chemo-resistant NSCLC, cell lines and clinical specimens, have been found to frequently possess one of a restricted number of loss-of-function somatic mutations in Keap1, which results in constitutively high levels of Nrf2 along with the cell protective proteins it regulates (Singh et al., 2006). Depletion of Nrf2, using siRNA or with small chemical molecules, results in dramatic sensitization of these cells to clinically relevant cytotoxics (Singh et al., 2008; Ren et al., 2011).

These are some examples of the challenge of identifying, validating and responding to clinical resistance to cancer therapies. Since they are frequently due to somatic genetic events in the

\section{REFERENCES}

Agoulnik, I. U., and Weigel, N. L. (2006). Androgen receptor action in hormone-dependent and recurrent prostate cancer. J. Cell. Biochem. 99, $362-372$.

Balk, S. P. (2002). Androgen receptor as a target in androgenindependent prostate cancer. Urology 60, 132-138.

Bartsch, R., Wenzel, C., Altorjai, G., Pluschnig, U., Rudas, M., Mader, R. M., Gnant, M., Zielinski, C. C., and Steger, G. G. (2007). Capecitabine and trastuzumab in heavily pretreated metastatic breast cancer. J. Clin. Oncol. 25, 3853-3858.

Baselga, J., and Mendelsohn, J. (1997). Type I receptor tyrosine kinases as targets for therapy in breast cancer. J. Mammary Gland Biol. Neoplasia 2, 165-174.
Batist, G., Kavan, P., Orain, M., Camlioglu, E., Aguilar-Mahecha, A., Basik, M., Rousseau, C., GagnonKugler, T., Spatz, A., and Têtu, B. (2010). "A biopsy-driven and biomarker discovery clinical trial in metastatic colorectal cancer led by a new Quebec-wide translational research network, to identify signatures of clinical resistance," in ESMO, Milan.

Berg, M., Danielsen, S. A., Ahlquist, T., Merok, M. A., Ågesen, T. H., Vatn, M. H., Mala, T., Sjo, O. H., Bakka, A., Moberg, I., Fetveit, T., Mathisen, Ø., Husby, A., Sandvik, O., Nesbakken, A., Thiis-Evensen, E., and Lothe, R. A. (2010). DNA sequence profiles of the colorectal cancer critical gene set KRAS-BRAF-PIK3CAPTEN-TP53 related to age at disease onset. PLoS ONE 5, e13978. doi:10.1371/journal.pone.0013978

tumor, they can be addressed in a fairly selective manner. There are a number of critical points to emphasize. A major challenge in identifying for study mechanisms of resistance to drugs that develops in the metastatic setting is ensuring that we examine the actual tissue that is clinically resistant; this of course requires biopsy of metastatic tumors at the start of therapy and at the advent of therapeutic resistance, with some assumption that tumor heterogeneity does not play a major role in secondary resistance. Although this represents both logistical and ethical challenges, we and others have successfully overcome them (Batist et al., 2010; Hilton et al., 2010). Tissue must be obtained in a manner that reliably preserves nucleic acids and morphology, and can be validated to be composed of at least "predominantly" tumor. An important challenge is to maintain control of both data and tissue sample flow, particularly when linking multiple clinical sites to major technology platforms. This is critical to preserve enough material for a range of analyses. To enhance the efficacy of analytical testing, it is critical to develop tumor type-specific multiplex tests that can be performed on minimal material in a CLIA-standard laboratory with a very strong program of quality control. Each multiplex technology has its own limits, and it is therefore crucial that rigorous qualification processes and external quality controls are in place. A good example in the literature is the Quebec-wide process for colon cancer-oriented multiplex ligation-dependent probe amplification (Jarry et al., 2011).

The data reviewed in these examples indicate the requirement for the development of next generation targeting agents that can overcome mechanisms of resistance caused by mutations in the target, and furthermore, that combinations of targeted agents will ultimately be necessary to anticipate and overcome therapeutic resistance related to non-target genes. Closer links between the clinic, molecular profiling expertise and mechanistic laboratories are essential to sort out which of the many somatic genetic events found in a given tumor is driving the tumor growth, which are potential escape paths that can become mechanisms of resistance and which are merely passengers with no immediate reason to target.

Chang, C. Y., Walther, P. J., and McDonnell, D. P. (2001). Glucocorticoids manifest androgenic activity in a cell line derived from a metastatic prostate cancer. Cancer Res. 61, 8712-8717.

Chapman, P. B., Hauschild, A., Robert, C., Haanen, J. B., Ascierto, P., Larkin, J., Dummer, R., Garbe, C., Testori, A., Maio, M., Hogg, D., Lorigan, P., Lebbe, C., Jouary, T., Schadendorf, D., Ribas, A., O’Day, S. J., Sosman, J. A., Kirkwood, J. M., Eggermont, A. M., Dreno, B., Nolop, K., Li, J., Nelson, B., Hou, J., Lee, R. J., Flaherty, K. T., McArthur, A. G., and BRIM-3 Study Group. (2011). Improved Survival with Vemurafenib in Melanoma with BRAF V600E Mutation. N. Engl. J. Med. 364, 2507-2516.

Choi, Y. L., Soda, M., Yamashita, Y., Ueno, T., Takashima, J., Nakajima,
T., Yatabe, Y., Takeuchi, K., Hamada, T., Haruta, H., Ishikawa, Y., Kimura, H., Mitsudomi, T., Tanio, Y., and Mano, H. (2010). ALK Lung Cancer Study Group. EML4ALK mutations in lung cancer that confer resistance to ALK inhibitors. N. Engl. J. Med. 363, 1734-1739.

Christodoulou, C., Kostopoulos, I., Kalofonos, H. P., Lianos, E. Bobos, M., Briasoulis, E., Gogas, H., Razis, E., Skarlos, D. V., Fountzilas, G., and Study of the Hellenic Cooperative Oncology Group. (2009). Trastuzumab combined with pegylated liposomal doxorubicin in patients with metastatic breast cancer. phase II Study of the Hellenic Cooperative Oncology Group (HeCOG) with biomarker evaluation. Oncology 76, 275-285. 
Corcoran, R. B., Dias-Santagata, D., Bergethon, K., Iafrate, A. J., Settleman, J., and Engelman, J. A. (2010). BRAF gene amplification can promote acquired resistance to MEK inhibitors in cancer cells harboring the BRAF V600E mutation. Sci. Signal. 3, ra84.

Culig, Z., Klocker, H., Bartsch, G., and Hobisch, A. (2002). Androgen receptors in prostate cancer. Endocr. Relat. Cancer 9, 155-170.

Davies, H., Bignell, G. R., Cox, C., Stephens, P., Edkins, S., Clegg, S., Teague, J., Woffendin, H., Garnett, M. J., Bottomley, W., Davis, N., Dicks, E., Ewing, R., Floyd, Y., Gray, K., Hall, S., Hawes, R., Hughes, J., Kosmidou, V., Menzies, A., Mould, C., Parker, A., Stevens, C., Watt, S., Hooper, S., Wilson, R., Jayatilake, H., Gusterson, B. A., Cooper, C., Shipley, J., Hargrave, D., Pritchard-Jones, K., Maitland, N., Chenevix-Trench, G., Riggins, G. J., Bigner, D. D., Palmieri, G., Cossu, A., Flanagan, A., Nicholson, A., Ho, J. W., Leung, S. Y., Yuen, S. T., Weber, B. L., Seigler, H. F., Darrow, T. L., Paterson, H., Marais, R., Marshall, C. J., Wooster, R., Stratton, M. R., and Futreal, P. A. (2002). Mutations of the BRAF gene in human cancer. Nature 417, 949-954.

De Roock, W., Jonker, D. J., Di Nicolantonio, F., Sartore-Bianchi, A., Tu, D., Siena, S., Lamba, S., Arena, S., Frattini, M., Piessevaux, H., Van Cutsem, E., O'Callaghan, C. J., Khambata-Ford, S., Zalcberg, J. R., Simes, J., Karapetis, C. S., Bardelli, A., and Tejpar, S. (2010). Association of KRAS p.G13D mutation with outcome in patients with chemotherapy-refractory metastatic colorectal cancer treated with cetuximab. JAMA 304, 1812-1820.

Dummer, R., Robert, C., Chapman, P. B., Sosman, J. A., Middleton, M., Bastholt, L., Kemsley, K., Cantarini, M. V., Morris, C. and Kirkwood, J. M. (2008). AZD6244 (ARRY142886) vs temozolomide (TMZ) in patients (pts) with advanced melanoma: an open-label, randomized, multicenter, phase II study. J. Clin. Oncol. 26, 9033.

Fedorenko, I. V., Paraiso, K. H., and Smalley, K. S. (2011). Acquired and intrinsic BRAF inhibitor resistance in BRAF V600E mutant melanoma. Biochem. Pharmacol. 82, 201-209.

Fornaro, L., Lucchesi, M., Caparello, C., Vasile, E., Caponi, S., Ginocchi, L., Masi, G., Falcone, A., and Medscape. (2011). Anti-HER agents in gastric cancer: from bench to bedside. Nat. Rev. Gastroenterol. Hepatol. 8, 369-383.

Gianni, L., Dafni, U., Gelber, R. D., Azambuja, E., Muehlbauer, S.,
Goldhirsch, A., Untch, M., Smith, I., Baselga, J., Jackisch, C., Cameron, D., Mano, M., Pedrini, J. L., Veronesi, A., Mendiola, C., Pluzanska, A., Semiglazov, V., Vrdoljak, E., Eckart, M. J., Shen, Z., Skiadopoulos, G., Procter, M., Pritchard, K. I., Piccart-Gebhart, M. J., Bell, R., and Herceptin Adjuvant (HERA) Trial Study Team. (2011) Treatment with trastuzumab for 1 year after adjuvant chemotherapy in patients with HER2-positive early breast cancer: a 4-year followup of a randomised controlled trial. Lancet Oncol. 12, 236-244.

Gu, L., Lau, S. K., Loera, S., Somlo, G., and Kane, S. E. (2009). Protein kinase A activation confers resistance to trastuzumab in human breast cancer cell lines. Clin. Cancer Res. 15, 7196-7206.

Hara, T., Miyazaki, J., Araki, H., Yamaoka, M., Kanzaki, N., Kusaka, M., and Miyamoto, M. (2003). Novel mutations of androgen receptor: a possible mechanism of bicalutamide withdrawal syndrome. Cancer Res. 63, 149-153.

Hilton, J. F., Amir, E., Hopkins, S., Nabavi, M., Diprimio, G., Sheikh, A., Done, S. J., Gianfelice, D., Kanji, F., Dent, S., Barth, D., Bouganim, N., Al-Najjar, A., and Clemons, M. (2010). Acquisition of metastatic tissue from patients with bone metastases from breast cancer. Breast Cancer Res. Treat. 29, 761-765.

Hochhaus, A., Kantarjian, H. M., Baccarani, M., Lipton, J. H., Apperley, J. F., Druker, B. J., Facon, T., Goldberg, S. L., Cervantes, F., Niederwieser, D., Silver, R. T., Stone, R. M., Hughes, T. P., Muller, M. C., Ezzeddine, R., Countouriotis, A. M., and Shah, N. P. (2007). Dasatinib induces notable hematologic and cytogenetic responses in chronic-phase chronic myeloid leukemia after failure of imatinib therapy. Blood 109, 2303-2309.

Infante, J. R., Falchook, G. S., Lawrence, D. P., Weber, J. S., Kefford, R. F. Bendell, J. C., Kurzrock, R., Shapiro, G., Kudchadkar, R. R., Long, G. V., Burris, H. A., Kim, K. B., Clements, A., Peng, S., Yi, B., Allred, A. J., Ouellet, D., Patel, K., Lebowitz, P. F., and Flaherty, K. T. (2011). Phase I/II study to assess safety, pharmacokinetics, and efficacy of the oral MEK $1 / 2$ inhibitor GSK1120212 (GSK212) dosed in combination with the oral BRAF inhibitor GSK2118436 (GSK436). J. Clin. Oncol. 29(Suppl.), CRA8503.

Jackisch, C. (2006). HER-2-positive metastatic breast cancer: optimizing trastuzumab-based therapy. Oncologist 11(Suppl. 1), 34-41.
Jarry, J., Brunet, J. S., Laframboise, R., Drouin, R., Latreille, J., Richard, C. Gekas, J., Maranda, B., Monczak, Y., Wong, N., Pouchet, C., Zaor, S., Kasprzak, L., Palma, L., Wu, M. K., Tischkowitz, M., Foulkes, W. D., and Chong, G. (2011). A survey of APC mutations in Quebec. Fam. Cancer. PMID: 21779980. [Epub ahead of print].

Jirawatnotai, S., Hu, Y., Michowski, W., Elias, J. E., Becks, L., Bienvenu, F., Zagozdzon, A., Goswami, T., Wang, Y. E., Clark, A. B., Kunkel, T. A., van Harn, T., Xia, B., Correll, M., Quackenbush, J., Livingston, D. M., Gygi, S. P., and Sicinski, P. (2011). A function for cyclin D1 in DNA repair uncovered by protein interactome analyses in human cancers. Nature 474, 230-234.

Johannessen, C. M., Boehm, J. S., Kim, S. Y., Thomas, S. R., Wardwell, L., Johnson, L. A., Emery, C. M., Stransky, N., Cogdill, A. P., Barretina, J., Caponigro, G., Hieronymus, H., Murray, R. R., Salehi-Ashtiani, K., Hill, D. E., Vidal, M., Zhao, J. J., Yang, X., Alkan, O., Kim, S., Harris, J. L., Wilson, C. J., Myer, V. E., Finan, P. M., Root, D. E., Roberts, T. M., Golub, T., Flaherty, K. T., Dummer, R., Weber, B. L., Sellers, W. R., Schlegel, R., Wargo, J. A., Hahn, W. C., and Garraway, L. A. (2010). COT drives resistance to RAF inhibition through MAP kinase pathway reactivation. Nature 468, 968-972.

Kataoka, Y., Mukohara, T., Shimada, H., Saijo, N., Hirai, M., and Minami, $H$. (2010). Association between gainof-function mutations in PIK3CA and resistance to HER2-targeted agents in HER2-amplified breast cancer cell lines. Ann. Oncol. 21, 255-262.

Kefford, R., Arkenau, H., Brown, M. P., Millward, M., Infante, J. R., Long, G. V., Ouellet, D., Curtis, M., Lebowitz, P. F., and Falchook, G. S. (2010). Phase I/II study of GSK2118436, a selective inhibitor of oncogenic mutant BRAF kinase, in patients with metastatic melanoma and other solid tumors. J. Clin. Oncol. 28, 8503.

Khambata-Ford, S., Garrett, C. R., Meropol, N. J., Basik, M., Harbison, C. T., Wu, S., Wong, T. W., Huang, X., Takimoto, C. H., Godwin, A. K., Tan, B. R., Krishnamurthi, S. S., Burris, H. A. III, Poplin, E. A., Hidalgo, M., Baselga, J., Clark, E. A., and Mauro, D. J. (2007). Expression of epiregulin and amphiregulin and K-ras mutation status predict disease control in metastatic colorectal cancer patients treated with cetuximab. J. Clin. Oncol. 25, 3230-3237.

Krishnan, A. V., Zhao, X. Y., Swami, S., Brive, L., Peehl, D. M., Ely, K.
R., and Feldman, D. (2002). A glucocorticoid-responsive mutant androgen receptor exhibits unique ligand specificity: therapeutic implications for androgenindependent prostate cancer. Endocrinology 143, 1889-1900.

Lázár, V., Ecsedi, S., Szöllosi, A. G., Tóth, R., Vízkeleti, L., Rákosy, Z., Bégány, A., Adány, R., and Balázs, M. (2009). Characterization of candidate gene copy number alterations in the $11 \mathrm{q} 13$ region along with BRAF and NRAS mutations in human melanoma. Mod. Pathol. 22 1367-1378.

Little, A. S., Balmanno, K., Sale, M. J., Newman, S., Dry, J. R., Hampson, M., Edwards, P. A., Smith, P. D., and Cook, S. J. (2011). A correction to the research article titled: "amplification of the driving oncogene, KRAS or BRAF, underpins acquired resistance to MEK1/2 inhibitors in colorectal cancer cells" by A. S. Little, K. Balmanno, M. J. Sale, S. Newman, J. R. Dry, M. Hampson, P. A. W. Edwards, P. D. Smith, S. J. Cook. Sci. Signal. 4, er2.

Loignon, M., Miao, W., Hu, L., Bier, A., Batist, Z., and Batist, G. (2009). Cul3 overexpression depletes Nrf2 in breast cancer and is associated with sensitivity to carcinogens, to oxidative stress, and to chemotherapy. Mol. Cancer Ther. 8, 2432-2440.

Lynch, T. J., Bell, D. W., Sordella, R., Gurubhagavatula, S., Okimoto, R. A., Brannigan, B. W., Harris, P. L., Haserlat, S. M., Supko, J. G., Haluska, F. G., Louis, D. N., Christiani, D. C., Settleman, J., and Haber, D. A. (2004). Activating mutations in the epidermal growth factor receptor underlying responsiveness of nonsmall-cell lung cancer to gefitinib. N. Engl. J. Med. 350, 2129-2139.

Mackay, A., Weigelt, B., Grigoriadis, A., Kreike, B., Natrajan, R., A'Hern, R., Tan, D. S., Dowsett, M., Ashworth, A., and Reis-Filho, J. S. (2011). Microarray-based class discovery for molecular classification of breast cancer: analysis of interobserver agreement. J. Natl. Cancer Inst. 103, 662-673.

Miyamoto, H., Rahman, M. M., and Chang, C. S. (2004). Molecular basis for the antiandrogen withdrawal syndrome. J. Cell. Biochem. 91, 3-12.

Montagut, C., Sharma, S. V., Shioda, T., McDermott, U., Ulman, M., Ulkus, L. E., Dias-Santagata, D., Stubbs, H., Lee, D. Y., Singh, A., Drew, L., Haber, D. A., and Settleman, J. (2008). Elevated CRAF as a potential mechanism of acquired resistance to BRAF inhibition in melanoma. Cancer Res. 68, 4853-4861. 
Nahta, R., and O'Regan, R. M. (2010). Evolving strategies for overcoming resistance to HER2-directed therapy: targeting the PI3K/Akt/mTOR pathway. Clin. Breast Cancer 10(Suppl. 3), S72-S78. [Review].

Nazarian, R., Shi, H., Wang, Q., Kong, X., Koya, R. C., Lee, H., Chen, Z., Lee, M. K., Attar, N., Sazegar, H., Chodon, T., Nelson, S. F., McArthur, G., Sosman, J. A., Ribas, A., and Lo, R. S. (2010) Melanomas acquire resistance to B-RAF(V600E) inhibition by RTK or N-RAS upregulation. Nature 468, 973-977.

Paez, J. G., Jänne, P. A., Lee, J. C., Tracy, S., Greulich, H., Gabriel, S., Herman, P., Kaye, F. J., Lindeman, N., Boggon, T. J., Naoki, K., Sasaki, H., Fujii, Y., Eck, M. J., Sellers, W. R., Johnson, B. E., and Meyerson, M. (2004). EGFR mutations in lung cancer: correlation with clinical response to gefitinib therapy. Science 304, 1497-1500.

Petrylak, D. P., Tangen, C. M., Hussain, M. H., Lara, P. N. Jr., Jones, J. A., Taplin, M. E., Burch, P. A., Berry, D., Moinpour, C., Kohli, M., Benson, M. C., Small, E. J., Raghavan, D., and Crawford, E. D. (2004). Docetaxel and estramustine compared with mitoxantrone and prednisone for advanced refractory prostate cancer. N. Engl. J. Med. 351, 1513-1520.

Press, M. F., Sauter, G., Bernstein, L., Villalobos, I. E., Mirlacher, M., Zhou, J. Y., Wardeh, R., Li, Y. T., Guzman, R., Ma, Y., Sullivan-Halley, J., Santiago, A., Park, J. M., Riva, A., and Slamon, D. J. (2005). Diagnostic evaluation of HER-2 as a molecular target: an assessment of accuracy and reproducibility of laboratory testing in large, prospective, randomized clinical trials. Clin. Cancer Res. 11, 6598-6607.

Ren, D., Villeneuve, N. F., Jiang, T., Wu, T., Lau, A., Toppin, H., and Zhang, D. D. (2011). Brusatol enhances the efficacy of chemotherapy by inhibiting the Nrf2-mediated defense mechanism. Proc. Natl. Acad. Sci. U.S.A. 108, 1433-1438.

Ryan, C. J., and Tindall, D. J. (2011). Androgen receptor rediscovered: the new biology and targeting the androgen receptor therapeutically. $J$. Clin. Oncol. 29, 3651-3658.

Sakai, W., Swisher, E. M., Karlan, B. Y., Agarwal, M. K., Higgins, J., Friedman, C., Villegas, E., Jacquemont, C., Farrugia, D. J., Couch, F. J., Urban, N., and Taniguchi, T. (2008). Secondary mutations as a mechanism of cisplatin resistance in BRCA2-mutated cancers. Nature 451, 1116-1120.
Sartore-Bianchi, A., Di Nicolantonio, F., Nichelatti, M., Molinari, F., De Dosso, S., Saletti, P., Martini, M., Cipani, T., Marrapese, G., Mazzucchelli, L., Lamba, S., Veronese, S., Frattini, M., Bardelli, A., and Siena, S. (2009). Multi-determinants analysis of molecular alterations for predicting clinical benefit to EGFR-targeted monoclonal antibodies in colorectal cancer. PLoS ONE 4, e7287. doi:10.1371/journal.pone.0007287

Sasaki, T., Koivunen, J., Ogino, A., Yanagita, M., Nikiforow, S., Zheng, W., Lathan, C., Marcoux, J. P., Du, J., Okuda, K., Capelletti, M., Shimamura, T., Ercan, D., Stumpfova, M., Xiao, Y., Weremowicz, S., Butaney, M., Heon, S., Wilner, K., Christensen, J. G., Eck, M. J., Wong, K. K., Lindeman, N., Gray, N. S., Rodig, S. J., and Janne, P. A. (2011). A novel ALK secondary mutation and EGFR signaling cause resistance to ALK kinase inhibitors. Cancer Res. 71, 6051-6060.

Shah, N. P., Nicoll, J. M., Nagar, B., Gorre, M. E., Paquette, R. L., Kuriyan, J., and Sawyers, C. L. (2002). Multiple BCR-ABL kinase domain mutations confer polyclonal resistance to the tyrosine kinase inhibitor imatinib (STI571) in chronic phase and blast crisis chronic myeloid leukemia. Cancer Cell 2, 117-125.

Sharfman, W. H., Hodi, F. S., Lawrence, D. P., Flaherty, K. T., Amaravadi, R. K., Kim, K. B., Dummer, R., Gobbi, S., Puzanov, I., Sosman, J. A., Dohoney, K., Lam, L. P., Kakar, S., Tang, Z., Krieter, O., and Atkins, M. B. (2011) Results from the first-inhuman (FIH) phase I study of the oral RAF inhibitor RAF265 administered daily to patients with advanced cutaneous melanoma. J. Clin. Oncol. 29, 8508.

Singh, A., Boldin-Adamsky, S., Thimmulappa, R. K., Rath, S. K., Ashush, H., Coulter, J., Blackford, A., Goodman, S. N., Bunz, F., Watson, W. H., Gabrielson, E., Feinstein, E., and Biswal, S. (2008). RNAi-mediated silencing of $\mathrm{Nrf}-2$-related factor 2 gene expression in non-small cell lung cancer inhibits tumor growth and increases efficacy of chemotherapy. Cancer Res. 68, 7975-7984.

Singh, A., Misra, V., Thimmulappa, R. K., Lee, H., Ames, S., Hoque, M. O., Herman, J. G., Baylin, S. B., Sidransky, D., Gabrielson, E., Brock, M. V., and Biswal, S. (2006). Dysfunctional KEAP1-NRF2 interaction in non-small-cell lung cancer. PLoS Med. 3, 1865-1876. doi:10.1371/journal.pmed.0030420 Smalley, K. S., Lioni, M., Dalla Palma, M., Xiao, M., Desai, B., Egyhazi, S.,
Hansson, J., Wu, H., King, A. J., Van Belle, P., Elder, D. E., Flaherty, K. T., Herlyn, M., and Nathanson, K. L. (2008). Increased cyclin D1 expression can mediate BRAF inhibitor resistance in BRAF V600E-mutated melanomas. Mol. Cancer Ther. 7, 2876-2883.

Steketee, K., Timmerman, L., Zielvan der Made, A. C. J., Doesburg, P., Brinkmann, A. O., and Trapman, J. (2002). Broadened ligand responsiveness of androgen receptor mutants obtained by random amino acid substitution of H874 and mutation hot spot $\mathrm{T} 877$ in prostate cancer. Int. J. Cancer 100, 309-317.

Tannock, I. F., de Wit, R., Berry, W. R., Horti, J., Pluzanska, A., Chi, K. N., Oudard, S., Théodore, C., James, N. D., Turesson, I. Rosenthal, M. A., Eisenberger, M. A., and TAX 327 Investigators. (2004). Docetaxel plus prednisone or mitoxantroneplus prednisone for advanced prostate cancer. N. Engl. J. Med. 351, 1502-1512.

Taplin, M. E. (2008). Androgen receptor: role and novel therapeutic prospects in prostate cancer. Expert Rev. Anticancer Ther. 8, 1495-1508.

Taplin, M. E., and Ho, S. M. (2001). The endocrinology of prostate cancer. J. Clin. Endocrinol. Metab. 86, 3467-3477.

Taplin, M. E., Rajeshkumar, B., Halabi, S., Werner, C. P., Woda, B. A., Picus, J., Stadler, W., Hayes, D. F., Kantoff, P. W., Vogelzang, N. J., Small, E. J., and Cancer and Leukemia Group B Study 9663. (2003). Androgen receptor mutations in androgen-in dependent prostate cancer: Cancer and Leukemia Group B Study 9663. J. Clin. Oncol. 21, 2673-2678.

Urushibara, M., Ishioka, J., Hyochi, N., Kihara, K., Hara, S., Singh, P., Isaacs, J. T., and Kageyama, Y. (2007). Effects of steroidal and non-steroidal antiandrogens on wild-type and mutant androgen receptors. Prostate 67, 799-807.

Villanueva, J., Vultur, A., Lee, J. T., Somasundaram, R., Fukunaga-Kalabis, M., Cipolla, A. K., Wubbenhorst, B., Xu, X., Gimotty, P. A., Kee, D., Santiago-Walker, A. E., Letrero, R., D'Andrea, K., Pushparajan, A., Hayden, J. E., Brown, K. D., Laquerre, S., McArthur, G. A., Sosman, J. A., Nathanson, K. L., and Herlyn, M. (2010). Acquired resistance to BRAF inhibitors mediated by a RAF kinase switch in melanoma can be overcome by cotargeting MEK and IGF-1R/PI3K. Cancer Cell 18, 683-695.

Wagle, N., Caroline, E., Berger, M. F., Davis, M. J., Sawyer, A., Pochanard, P., Kehoe, S. M., Johannessen, C.
M., MacConaill, L. E., Hahn, W. C., Meyerson, M., and Garraway, L. A. (2011). Dissecting therapeutic resistance to RAF inhibition in melanoma by tumor genomic profiling. J. Clin. Oncol. 29, 3085-3096.

Wan, P. T., Garnett, M. J., Roe, S. M., Lee, S., Niculescu-Duvaz, D., Good, V. M., Jones, C. M., Marshall, C. J., Springer, C. J., Barford, D., Marais, R., and Cancer Genome Project. (2004). Mechanism of activation of the RAF-ERK signaling pathway by oncogenic mutations of B-RAF. Cell 116, 855-867.

Wu, J. Y., Wu, S. G., Yang, C. H., Gow, C. H., Chang, Y. L., Yu, C. J., Shih, J. Y., and Yang, P. C. (2008). Lung cancer with epidermal growth factor receptor exon 20 mutations is associated with poor gefitinib treatment response. Clin. Cancer Res. 14, 4877-4882.

Zhang, S., Huang, W. C., Li, P., Guo, H., Poh, S. B., Brady, S. W., Xiong, Y., Tseng, L. M., Li, S. H., Ding, Z. Sahin, A. A., Esteva, F. J., Hortobagyi, G. N., and Yu, D. (2011) Combating trastuzumab resistance by targeting SRC, a common node downstream of multiple resistance pathways. Nat. Med. 17, 461-469.

Zhou, J., Geng, G., Shi, Q., Sauriol, F., and Wu, J. H. (2009). Design and synthesis of androgen receptor antagonists with bulky side chains for overcoming antiandrogen resistance. J. Med. Chem. 52, 5546-5550.

Conflict of Interest Statement: The authors declare that the research was conducted in the absence of any commercial or financial relationships that could be construed as a potential conflict of interest.

Received: 18 August 2011; accepted: 21 September 2011; published online: 05 October 2011.

Citation: Batist G, Wu JH, Spatz A, Miller Jr. WH, Cocolakis E, Rousseau C, Diaz Z, Ferrario C and Basik M (2011) Resistance to cancer treatment: the role of somatic genetic events and the challenges for targeted therapies. Front. Pharmacol. 2:59. doi: 10.3389/fphar.2011.00059 This article was submitted to Frontiers in Pharmacology of Anti-Cancer Drugs, a specialty of Frontiers in Pharmacology. Copyright (0) 2011 Batist, Wu, Spatz, Miller Jr., Cocolakis, Rousseau, Diaz, Ferrario and Basik. This is an open-access article subject to a non-exclusive license between the authors and Frontiers Media $S A$, which permits use, distribution and reproduction in other forums, provided the original authors and source are credited and other Frontiers conditions are complied with. 